\title{
Deflagration to detonation transition fueled by dust layers
}

\author{
Y.-C. Li, A.S. Harbaugh, C.G. Alexander, C.W. Kauffman, M. Sichel \\ Department of Aerospace Engineering, The University of Michigan, Ann Arbor, MI 48109-2140, USA
}

Received August 1, 1993 / Accepted February 27, 1995

\begin{abstract}
The roles which dust layers play in severe dust explosions were investigated in a $70 \mathrm{~m}$ long and $30 \mathrm{~cm}$ inside diameter horizontal Flame Acceleration Tube (FAT) with one end closed and the other end open to the atmosphere. A variety of dusts such as corn dust, cornstarch, Mira Gel starch, wheat dust, and wood flour were layered on the bottom half of the FAT. To initiate the combustion process, a detonation tube filled with a stoichiometric $\mathrm{H}_{2} / \mathrm{O}_{2}$ mixture at room temperature and $1 \mathrm{~atm}$ pressure was used to ignite a short presuspended dust cloud with a dust concentration of $500-600 \mathrm{~g} / \mathrm{m}^{3}$. Combustion waves generated by this dust cloud travel toward the open end of the FAT and are continuously fueled by the dust/air mixtures. Flame propagation processes in the FAT were closely monitored by a variety of measuring instruments at different locations. The study demonstrates that stable quasi-detonation were reached in some runs, but self-sustained Chapman-Jouguet detonations were not observed possibly due to the 1 imitation of the tube length. Attempts were made to determine the structure of dust detonations fueled by a dust layer. Preliminary evidence indicates that for Mira Gel starch the leading shock is essentially a triple shock configuration which involves a Mach stem and for wheat and wood dusts there possibly exists a multi-headed spin structure.
\end{abstract}

Key words: Detonation, Shock wave, Heterogeneous combustion, Dust explosion, Supersonic combustion, Unsteady flame

\section{Introduction}

Dust layers are commonly found in the places such as coal mines, food processing, wood processing, paper manufacturing and pharmaceutical plants, and metallurgical industries, and grain elevators. These various types of dust could be the products, by-products, or raw materials of these industries. Unusual currents of air may disperse such dust layer providing favorable conditions, where none existed before, to support a dust explosion. If there exists an ignition source to initiate a local or primary dust explosion, the compression waves induced by the explosion may violently disperse the dust layers which will drastically enhance the explosion process and may result in loss of life and/or property damage. It is, therefore, of great importance to investigate the mechanism of dust explosions fueled by combustible dust layers. The research on dust explosions was first conducted on coal dust as early as the mid-nineteenth century. After many explosion accidents in the European coal mines, people gradually realized the hazards of coal dust (Verakis and Nagy 1987). Grain dust explosions, however, did not draw enough scientific attention until the late 1970s. Since then tremendous efforts have been made to understand the fundamentals of dust explosions. The progress in dust explosion research has been summarized by Lee (1988) and Kauffman et al. (1991). Research activities on agricultural dust explosion at The University of Michigan are well-documented by Kauffman et al. (1992). Investigations of explosions fueled by combustible dust layers have been carried out for nearly a decade and are part of the series efforts to understand the fundamental mechanism on dust explosions.

The authors' previous study (Li et al. 1993) has presented strong evidence that detonation or quasi-detonation can be achieved in initially layered grain dust with ambient air as oxidizer. Such a transition is illustrated in Fig. 1 taken from this study. This figure shows the variation or pressure with time at various stations along the FAT and also shows the trajectory of the flame propagating down the FAT, based on photo diode measurements. As shown in Fig. 1, the flame front accelerates rapidly in the second half of the FAT, while pressure waves associated with the flame coalesce into strong shocks. A sudden increase of maximum pressure can be observed between $x=45$ and $64 \mathrm{~m}$ from approximately 7 to $26 \mathrm{~atm}$ and an increase in flame velocity from approximately 440 to $1400 \mathrm{~m} / \mathrm{s}$. A wave originating from this location travels back to the closed end of the FAT at a nearly constant velocity, at the local speed of sound and when it reaches the closed end of the FAT a reflected wave emerges traveling toward the open end, also at the local speed of sound. The wave traveling backwards is very typical of DDT in gaseous detonations, and was first identified and named retonation 


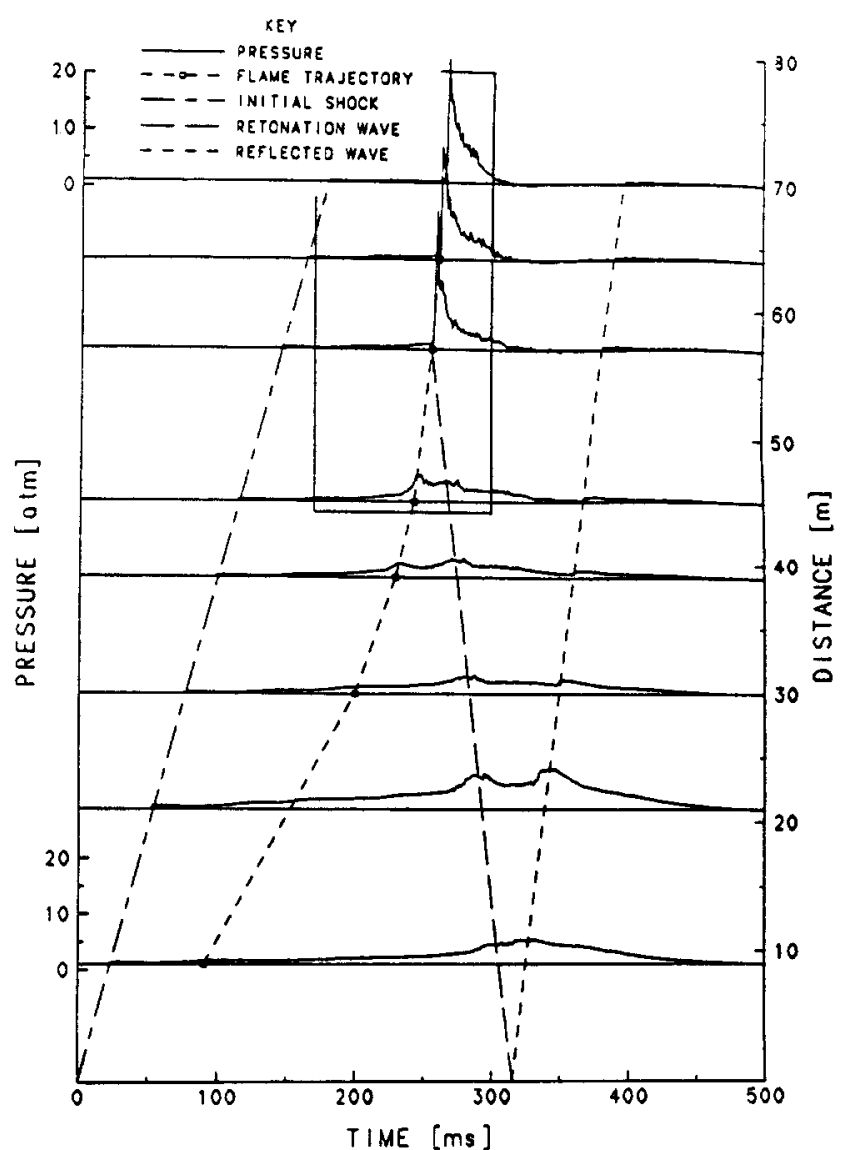

Fig. 1. Pressure histories at eight measuring stations in the FAT with flame trajectory shown. Dust layer: wheat, concentration $\sigma=400 \mathrm{~g} / \mathrm{m}^{3}, 8<x<$ $36 \mathrm{~m}, 300 \mathrm{~g} / \mathrm{m}^{3}, 33<x<67 \mathrm{~m}$. Pre-mixed initiator section: cornstarch, concentration $500 \mathrm{~g} / \mathrm{m}^{3}$ ( $\mathrm{Li}$ et al. 1993)

wave by Dixon nearly a century ago. There was evidently an explosion occurring between $x=45$ and $64 \mathrm{~m}$. This is the "Explosion within an explosion" noted by Urtiew and Oppenheim (1966) and is a very typical phenomenon when DDT occurs. There are also significant differences between the structure of gaseous and heterogeneous detonations. Thus Zhang and Groenig (1991) observed a spin like structure in detonations propagating through a pre-mixed cloud of corn starch and oxygen over a wide range of concentrations in contrast to very reactive gaseous fuels for which such structures only occur in mixtures very close to the detonation limit. It should be noted that for non reactive gaseous explosives such as methane spin also is observed over a wide range of mixture ratios.

As already indicated, the existence of DDT supported by dust layers in air has been established ( $\mathrm{Li}$ et al. 1993). The present paper presents the results of a more detailed investigation of this phenomenon and is a continuation of the previous study. The effects of initiator strength on the propagation of the dust flame was investigated. Grids were inserted in the FAT to establish how the turbulence these generate affects the flame velocity and pressure. The variation of flame velocity with distance along the FAT determines the transition distance, which is a key parameter in DDT. The variation of this velocity was measured for several different dusts and dust concentrations and compared to the results of other investigators. The measured velocities near the end of the FAT were compared to those computed using the Gordon-McBride Code (1971) to see how closely these velocities approach the ideal value in the case of layered dust detonations. Finally the traces of four pressure transducers placed circumferentially around the FAT at one measuring station were compared in order to gain some insight into the structure of layered dust detonations. These results are described in detail below.

\section{Experimental setup}

The experimental arrangement is basically the same as that used by Li et al. (1993), and a detailed description was given by $\mathrm{Li}$ (1993). The Flame Acceleration Tube (FAT) is a horizontal pipe with one end closed and the other open to ambient air. A schematic diagram of the FAT is shown in Fig. 2, and consists of a $71 \mathrm{~m}$ long steel tube with an inside diameter of $30 \mathrm{~cm}$. The FAT is instrumented with static pressure transducers, dynamic pressure transducers, and photo diodes at eight stations along the tube as shown in Fig. 2. A fourwavelength optical pyrometer is mounted near the end of the tube. Six pressure switches are distributed along last $20 \mathrm{~m}$ of the FAT. The data acquisition system is composed of a 64 channel, $2 \mathrm{kHz}$ analog to digital converter - a LeCroy $8212 \mathrm{~A}$ system, and an IBM Personal Computer AT. Four Kistler 603B 1 pressure transducers are installed around the circumference at $90^{\circ}$ intervals at a distance of $60 \mathrm{~m}$ from the closed end. Tektronix 7D20 digital oscilloscopes are employed to record the signals from these Kistler transducers and from PCB 102A pressure transducers and photo diodes at the last two stations. The initiator assembly, as also shown in Fig. 1, consists of a $2.44 \mathrm{~m}$ long and $5.08 \mathrm{~cm}$ inside diameter detonation tube and a three meter long V-channel within the FAT. The detonation tube, separated from the FAT by a Mylar diaphragm, is filled with an $\mathrm{H}_{2} / \mathrm{O}_{2}$ mixture.

A specially designed cart, equipped with a six liter dust pan, an auger, two motors (one driving the auger and the other the cart ) and a fan, is used to travel inside the FAT and deposit the dust layer on the bottom of the FAT with the desired concentration, which can be adjusted by varying the auger speed. It is important to note that the dust layer concentrations which is cited in the discussion below are nominal values based on the assumption that all of the dust in the layer is uniformly dispersed through the FAT prior to combustion. Generally this will not be the case; not all of the dust is always dispersed and the distribution across the FAT will not be uniform. The actual dust distribution after dispersal can only be determined by careful concentration measurements, and these are not, so far, available. As will be evident from the results below, the dispersion process has a dominant influence of the flame acceleration and DDT.

Operationally, the wheat dust is loaded into the main section of the FAT with the desired concentration by the cart. In the initiator section of the FAT, cornstarch is laid along a V-channel. The weight of the dust is controlled so that a dust cloud with the concentration of $500-600 \mathrm{~g} / \mathrm{m}^{3}$ can be generated above the $\mathrm{V}$-channel. The detonation tube is filled with a stoichiometric $\mathrm{H}_{2} / \mathrm{O}_{2}$ mixture with a pressure of $1 \mathrm{~atm}$ abs. High pressure air $(20 \mathrm{~atm})$ is discharged through the $\mathrm{V}$ channel, suspending the dust in the initiator. After a $0.25 \mathrm{~s}$ 


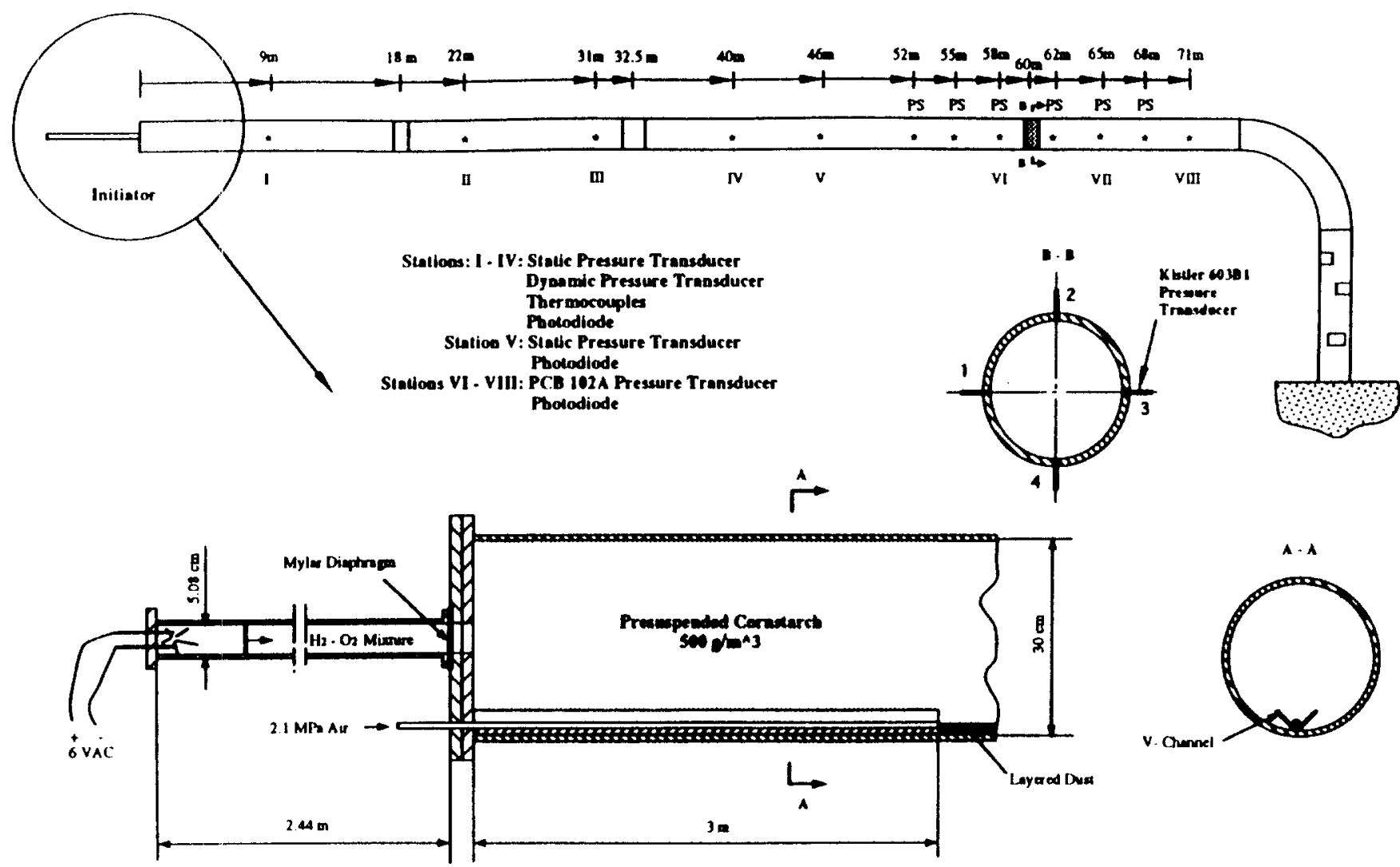

Fig. 2. Schematic diagram of the Flame Acceleration Tube (FAT)

delay, a glow plug ignites the gas mixture in the detonation tube, which then ignites the suspended dust cloud, leading to the combustion of the layered dust in the rest of the FAT. The energy release by the ignition process is negligibly small, compared with that of the later detonation process.

\section{Results and discussion}

\section{I Effects of initiator strength}

The energy of the initiation source must be above a certain value to ignite dust mixtures, and the minimum ignition energy is, thus, one of the important parameters affecting the likelihood that a dust explosion will occur. The effects of the initiator strength on the generation of layered dust explosions were therefore were investigated in the present study. First, initiation with the $\mathrm{H}_{2} / \mathrm{O}_{2}$ detonation tube alone was tested. The results showed that this method consistently fails to ignite the dust layers since the FAT behaves as if no dust were present. The $\mathrm{H}_{2} / \mathrm{O}_{2}$ ignitor alone apparently does not meet the requirement of the minimum ignition energy. This simple test indicates that the use of a dust cloud in the first three meters or primary section of the FAT is essential for ignition. This primary section thus plays the same role as the local or primary explosion in an accidental dust explosion.

The initiation strength can be varied by changing the concentration and/or the type of dust in the primary or premixed section of the FAT. Figure 3(a) and (b) compare the performance of the initiator with concentrations of 500 and
$600 \mathrm{~g} / \mathrm{m}^{3}$ of Mira Gel dust in the primary section. Each of the curves represents an average value of three repeated runs. From Fig. 3(a) and (b), it can be seen that the $500 \mathrm{~g} / \mathrm{m}^{3}$ runs generate higher maximum pressures at $x=58$ and $65 \mathrm{~m}$ and flame velocities at $x=52$ and $61.5 \mathrm{~m}$ than do the runs with the $600 \mathrm{~g} / \mathrm{m}^{3}$. Here $x$ denotes the distance from the closed end of the FAT. The differences shown here do not seem to be very significant which is not surprising since the variation of the primary concentration was not large. Because of the large scatter in the data, it is difficult to draw firm conclusions about the effects of the primary concentration on the whole combustion process for the range of primary concentrations considered. For reference, Lebecki et al. (1991) in a study conducted in an experimental mine found that the generation of pre-layered dust combustion strongly depended on initiation strength. The most significant result here was to demonstrate the need for a primary pre-mixed dust explosion to ignite a layered dust explosion in the FAT.

\subsection{Effects of inserted grids}

In the case of gaseous explosives turbulence has been found to have a significant effect on DDT. One set of horizontal bars and one set of grids were installed in the FAT at $x=18$ and $33 \mathrm{~m}$, respectively in order to examine this effect in layered dust explosions. For the sake of simplicity, these set are called the grids. The results of the runs with the grids are compared to those without the grids in Fig. 4(a) and (b) for a Mira Gel dust layer with a concentration of $500 \mathrm{~g} / \mathrm{m}^{3}$. In Fig. 4(a) the maximum pressure shows no significant difference until the flame reaches $x=50 \mathrm{~m}$ where the pressurc 

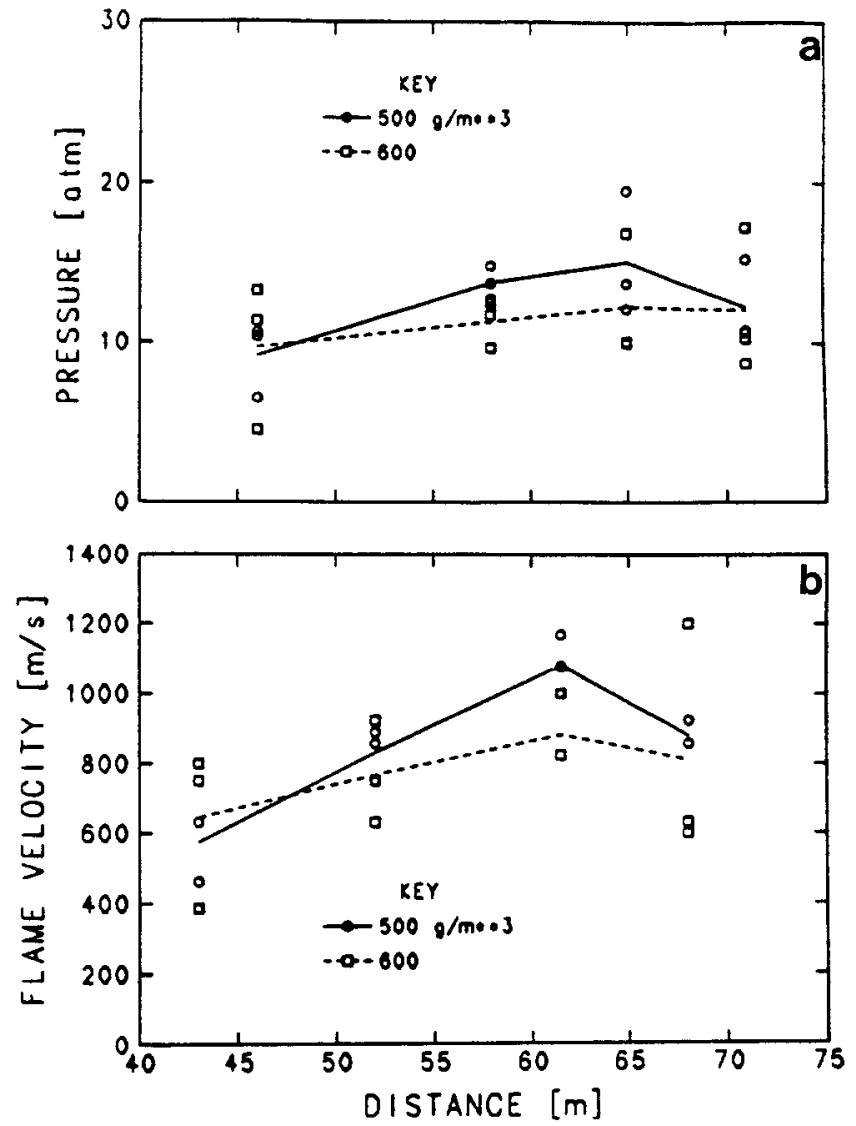

Fig. 3a,b. Maximum pressures and flame velocities for different dust concentrations in the pre-mixed initiator section. Dust layer: Mira Gel, $\sigma=500 \mathrm{~g} / \mathrm{m}^{3}$, layer length $67 \mathrm{~m}$. a Maximum pressure; b Flame velocity

for the run with the grids becomes higher than for that without grids. In Fig. 4(b) the flame velocity without the grids initially is higher. However, the flame for the run with grids accelerates faster than that without, and outpaces the gridless velocity after $x>50 \mathrm{~m}$. There are two possible explanations for this effect. First the presence of the grids intensifies the turbulent intensity of the flow field even though there are relatively few grids in the tube. As already indicated, turbulence plays an important role in gaseous detonations, and this should remain the case for heterogeneous reactive systems. Second, the blockage of the tube by the grids locally increases the velocity of the flow which may lead to enhanced dispersion of the dust layer. The mixing process is one of the main driving factors in layered dust detonation. It is certain that both turbulence and enhanced mixing contribute to a stronger more rapid DDT; however, it is not clear which one of these plays the most important role.

\subsection{Transition distance}

The transition distance is a very important characteristic parameter in DDT and will, in many cases, indicate the likelihood that transition to detonation will occur. Some of the main parameters governing this distance are the tube dimension and geometry, the wall roughness, the nature, strength and location of the ignition source, the boundary conditions, i.e. closed vs. open ended tubes, and the heat of combustion and reaction kinetics of the fuel. These parameters contribute
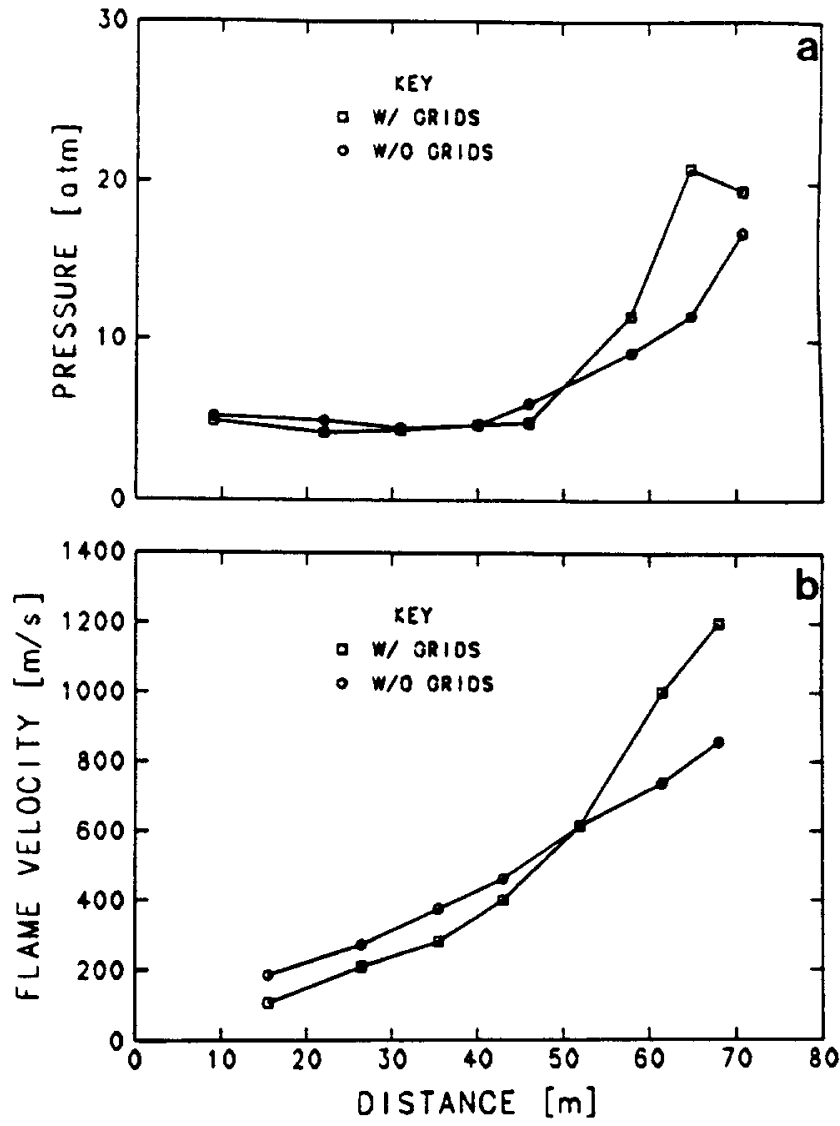

Fig. 4a,b. The effect of grids on the maximum pressure and flame velocity. Dust layer: Mira Gel, $\sigma=500 \mathrm{~g} / \mathrm{m}^{3}$. a Maximum pressure; b Flame velocity

to the level of turbulence, and the shock flame interactions which are two of the main flame acceleration mechanisms leading to transition. In order to compare transition distances for dust detonations, measured under various conditions the variation of flame velocity with distance normalized by tube diameter as measured by several investigators and in the FAT is shown in Fig. 5.

In addition to the present results, those of Wolanski et al. (1990), Zhang and Groenig (1991), Matsui and Komamiya (1986), and Cybulski (1975) are shown in Fig. 5. A comparison of experimental facilities and test methods used by these authors are presented in Table 1. Wolanski et al. (1990) used a $13 \mathrm{~m}$ long and $13 \mathrm{~cm}$ i.d. vertical tube, and Zhang and Groenig (1991) used a $17.4 \mathrm{~m}$ long and $14.1 \mathrm{~cm}$ i.d. horizontal tube. Pre-suspended dust and strong shock initiation were used in both studies, while the Zhang and Groenig used pure oxygen to enhance the combustion process. Matsui and Komamiya (1986) used a $5.2 \mathrm{~m}$ long and $2.8 \mathrm{~cm}$ i.d. tube coated with soot particles formed from the burning of acetylene. Technically, this work does not belong to the category of dust combustion, because a) the sizes of soot particles are in range of $5-10 \mathrm{~nm}$, while small conventional dust particles of interest in most dust explosions are generally in the range of 5-400 $\mu \mathrm{m}$ in diameter, and b) these soot particles contains a large proportion of hydrogen. Cybulski (1975) studied coal dust flame propagation in a $400 \mathrm{~m}$ long gallery in an experimental mine. The maximum height of the gallery $(2.65 \mathrm{~m})$ was chosen as the characteristic length 


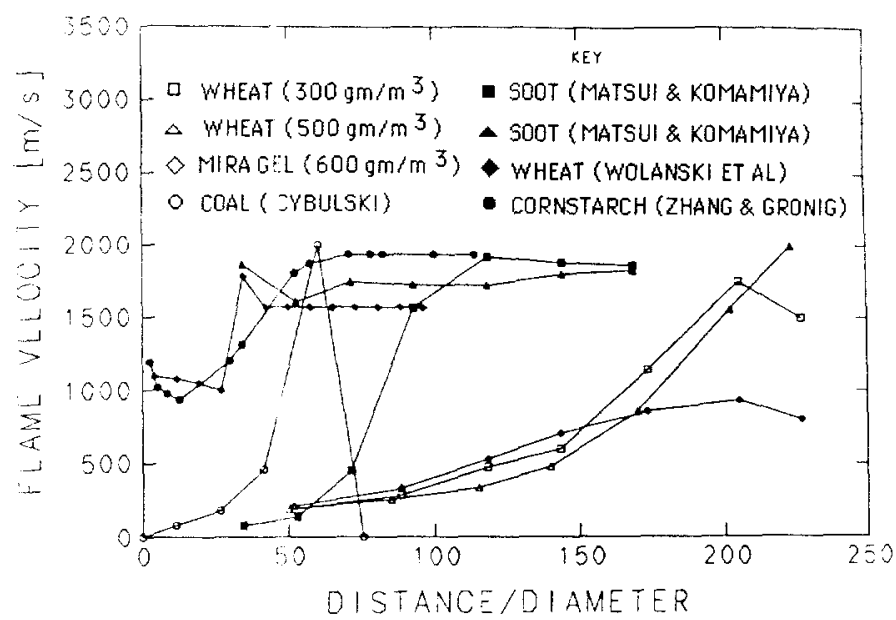

Fig. 5. Flame propagaticn velocity as a function of $x / d$, the ratio of distance to tube diameter. Resuls shown: Wolanski et al. (1990), corn starch presuspended in air, $\sigma=500 \mathrm{~g} / \mathrm{m}^{3}, d=13 \mathrm{~cm}$; Zhang and Groenig (1991), corn starch pre-suspended in $\mathrm{O}_{2}, \sigma=500 \mathrm{~g} / \mathrm{m}^{3}, d=14.1 \mathrm{~cm}$; Matsui and Komamiya (1986), soot coating in $\mathrm{O}_{2}, d=2.8 \mathrm{~cm}$; Cybulski (1975), coal dust, pre-layered in air, $d$ (equivalent) $=265 \mathrm{~cm}$

in determining $x / d$. The dust was layered on the floors and shelves of the gallery for a distance of $200 \mathrm{~m}$. The ignitor was located in the middle of the $400 \mathrm{~m}$ gallery so that the flame essentially propagated from an open toward a closed end, thus providing a very different boundary condition from the other investigations compared here.

From Fig. 5 it can be seen that stable detonations propagating at a constant velocity were achieved using direct or shock initiation by Wolanski et al. (1990), Zhang and Groenig (1991), and Matsui and Komamiya (1986) in a distance on the order of 50 tube diameters. Matsui and Komamiya also achieved a stable detonation with self initiation but the transition distance was doubled to about 100 tube diameters. Detonation velocity also was reached by Cybulski (1975) in pre-layered dust at a distance of about 50 characteristic lengths after which the velocity dropped to zero because of the conditions of the experiment.

The flame velocity in the FAT for wheat with concentration $\sigma=300 \mathrm{~g} / \mathrm{m}^{3}$ increases to about $1750 \mathrm{~m} / \mathrm{s}$ with distance until $x / d \approx 210$ after which it decelerates to $1500 \mathrm{~m} / \mathrm{s}$ at the end of the FAT. For the richer flame with $\sigma=500 \mathrm{~g} / \mathrm{m}^{3}$ the velocity accelerates continuously until it reaches a value of about $2000 \mathrm{~m} / \mathrm{s}$ at the end of the FAT. While the pressure protiles and flame trajectories in Fig. 1, and others like it [ $\mathrm{Li}$ et al. 1993; Li 1993] indicate that transition to detonation has occurred, it is not clear from the results shown in Fig. 5 that this layered dust detonation is stable and would continue to propagate al a constant velocity or whether it would propagate as a galloping detonation or possibly extinguish. A tube much longer than the FAT would be required to establish the behavior of the layered dust detonation after DDT has occurred. In the case of Mira Gel dust the flame reaches a constant velocity of about $900 \mathrm{~m} / \mathrm{s}$ at $\mathrm{x} / \mathrm{d} \approx 170$ and this wave can be considered to be a quasi-detonation.

It is, perhaps, questionable to compare results at the same value of the normalized distance $x / d$ since the boundary conditions for each of the experiments described above are different. However, the results do indicate that the DDT tran- sition distance for layered dust detonations is about twice that for pre-dispersed dust detonations, probably because reaction between the dust particles and the oxidizer must be preceded by the relatively slow dust/oxidizer mixing process. The comparison of results in Fig. 5 indicates that DDT is favored by pre-mixing of the dust and oxidizer, direct or blast vs. self initiation, and enrichment of air by oxygen or replacement by pure oxygen.

\subsection{Comparison of computed and measured detonation velocity}

It is important to compare the measured and computed detonation velocities in order to see how closely the actual wave approaches an ideal Chapman-Jouguet detonation at the end of the DDT. The theoretical C-J detonation velocity was calculated for wheat dust using the Gordon-McBride (1971) code. An approximate chemical formula for wheat dust, which is needed for this calculation (Srinath 1985), can be written as:

$$
\begin{aligned}
\mathrm{C}_{3.574} \mathrm{H}_{5.892} \mathrm{O}_{2.589} \mathrm{~N}_{0.076}+3.75\left(\mathrm{O}_{2}+3.76 \mathrm{~N}_{2}\right) \\
\rightarrow 3.574 \mathrm{CO}_{2}+2.946 \mathrm{H}_{2} \mathrm{O}+14.144 \mathrm{~N}_{2} .
\end{aligned}
$$

The heat of reaction of wheat dust is $-14.76 \mathrm{~kJ} / \mathrm{g}$, and it follows that the heat of formation of wheat dust calculated from the above chemical formula is $-756.4 \mathrm{~kJ} / \mathrm{mole}$. The initial conditions used in the computation are $P_{0}=1 \mathrm{~atm}$ and $\mathrm{T}_{0}=298 \mathrm{~K}$. The calculations are based on the following assumptions: 1) the volume of the dust is negligibly small, 2) oxidizers contained inside the dust particles are negligible, 3) the dust is uniformly distributed, i.e., dust concentration is constant everywhere inside the tube, and 4) all the dust takes part in the combustion and reactions are complete. The Gordon-McBride code (1971) is based on the assumption that the products of combustion downstream of the detonation are in chemical equilibrium.

Measured and calculated velocities, pressures and temperatures are tabulated in Table 2 for dust concentrations ranging from $250-500 \mathrm{~g} / \mathrm{m}^{3}$. The measured flame velocities shown in the first column were measured at the locations $x=60-70 \mathrm{~m}$ or $x / d=200-230$ using photo diode responses. As is evident from Fig. 5, the flame velocity is close to the maximum value at these locations. The values computed using the Gordon-McBride code are shown in the next column. In the case of detonations or quasi-detonations it seems more appropriate to measure propagation velocities based on pressure transducer responses which sense the passage of the leading shock wave, and these values are shown in the third column. Table 2 also shows the calculated and measured pressures behind the detonation and the maximum pressure observed during the DDT in the FAT.

From Table 2, it can be seen that the calculated velocity, pressure, and temperature decrease as the concentration increases. The measured values of flame and detonation velocity and pressure peak at concentrations of $\sigma=300-$ $350 \mathrm{~g} / \mathrm{m}^{3}$. Measured temperatures do not appear to be sensitive to the variation in concentration in contrast to computed values. This disagreement may be due to the fact that the thermocouples used to measure temperature were not sufficiently sensitive. Measured pressures were always higher 
Table 1. Comparison among test conditions of this study and others

\begin{tabular}{|c|c|c|c|c|c|}
\hline Investigation & $\begin{array}{l}\text { Tube } \\
\text { Length } \\
\text { (m) }\end{array}$ & $\begin{array}{l}\text { Tube } \\
\text { Diameter } \\
(\mathrm{cm})\end{array}$ & Initation & $\begin{array}{l}\text { Loading } \\
\text { Pattern }\end{array}$ & Oxidizer \\
\hline This Study & 71 & 29.85 & Self & Pre-layered & Air \\
\hline Cybulsky (1975) & 200 & 265 & Direct & Pre-layered & Air \\
\hline Matsui and Komamiya (1986) & 5.2 & 2.8 & Both & Film coated & Oxygen \\
\hline Wolanski et al. (1990) & 13 & 13 & Direct & Pre-suspended & Air \\
\hline Zhang and Groenig (1991) & 17.4 & 14.1 & Direct & Pre-suspended & Oxygen \\
\hline
\end{tabular}

Table 2. Comparison between calculated and measured detonation parameters

\begin{tabular}{|c|c|c|c|c|c|c|c|c|}
\hline $\begin{array}{l}\text { Concentration } \\
\left(\mathrm{g} / \mathrm{m}^{3}\right)\end{array}$ & $\begin{array}{l}\text { Measured } \\
\text { flame } \\
\text { velocity } \\
(\mathrm{m} / \mathrm{s})\end{array}$ & $\begin{array}{l}\text { Calculated } \\
\text { detonation } \\
\text { velocity } \\
(\mathrm{m} / \mathrm{s})\end{array}$ & $\begin{array}{l}\text { Measured } \\
\text { quasi- } \\
\text { detonation } \\
\text { (detonation) } \\
\text { velocity } \\
(\mathrm{m} / \mathrm{s})\end{array}$ & $\begin{array}{l}\text { Calculated } \\
\text { detonation } \\
\text { pressure } \\
\text { (atm) }\end{array}$ & $\begin{array}{l}\text { Measured } \\
\text { and max } \\
\text { pressure } \\
\\
P \\
\text { (atm) }\end{array}$ & $\begin{array}{l}\left(P_{\max }\right) \\
(\mathrm{atm})\end{array}$ & $\begin{array}{l}\text { Calculated } \\
\text { temperature } \\
(\mathrm{K})\end{array}$ & $\begin{array}{l}\text { Measured } \\
\text { temperature } \\
\text { (K) }\end{array}$ \\
\hline 250 & 1070 & 1651 & 1200 & 16.8 & 23 & (40) & 2461 & 1670 \\
\hline 300 & $1470-1790$ & 1581 & $1420-1700$ & 15.4 & 26 & (62) & 2183 & $\sim 1800$ \\
\hline 350 & $>1400$ & 1498 & $1250-1650$ & 14.1 & 26 & (55) & 1909 & $\sim 1800$ \\
\hline 400 & 1625 & 1410 & $1200-1550$ & 12.8 & 24 & $(45)$ & 1654 & $1700-1800$ \\
\hline 450 & 1395 & 1321 & 1300 & 11.4 & 24 & (35) & 1424 & $\sim 1600$ \\
\hline 500 & $1200-1400$ & 1226 & $1100-1180$ & 10.1 & $16-21$ & (32) & 1213 & $1680-1800$ \\
\hline
\end{tabular}

than computed values while the maximum pressure $\mathrm{P}_{\max }$ was much higher. Such high pressures typically occur during DDT just before a detonation or quasi-detonation is established.

Comparing the experimental and calculated results, it can be seen that both measured and computed detonation velocities are in reasonable agreement, which may indicate that C-J velocities have been reached toward the end of the FAT. But as already indicated above, due to the limited tube length, it is premature to conclude that stable C-J detonations have been achieved in the FAT. Disagreement between measured and computed values may in part be due to incomplete dispersion of the dust layer. The calculations are based on the assumption that the dust in the layer on the bottom of the FAT is uniformly distributed throughout the tube, but this is not generally the case.

\subsection{Layered detonation structure}

The structure of the reaction zone has a large influence on the propagation of detonations in tubes. Even in the case of gaseous detonations the structure is extremely complex and typically involves a system of transverse waves and associated triple points traversing the detonation front. This structure becomes even more complex when the explosive concentration ahead of the wave is not uniform. A qualitative understanding of the structure of gaseous detonations has been developed using flow visualization techniques as, for example, Schlieren framing photography; however, since conventional light rays cannot readily penetrate dust clouds, it is impossible to utilize such techniques to study the structure of pre-dispersed or layered dust detonations. Limited success in the direct filming of the flow field in dust flames was achieved in the FAT; however, it was still impossible to obtain a clear picture showing the leading shock waves and the following compression or expansion waves. Furthermore, the high pressure within the flow field, particularly during DDT, prohibits the installation of windows large enough to visually observe the combustion processes. Consequently no attempt was made in this study to visualize the detonation structure; however, some understanding of the detonation structure can be obtained by carefully examining the pressure traces measured using transducers placed at one $x$ location around the circumference of the FAT.

Figure 6 shows an example of the pressure traces measured around the circumference of the FAT at $x=60 \mathrm{~m}$ for dry Mira Gel dust at a nominal concentration: $\sigma=600 \mathrm{~g} / \mathrm{m}^{3}$. The pre-dispersed section was loaded with cornstarch with concentration $\sigma=500 \mathrm{~g} / \mathrm{m}^{3}$. As already indicated in the discussion above, a quasi-detonation is formed near the end of the FAT propagating at about half the C-J velocity. The pressures were measured using Kistler $603 \mathrm{~B} 1$ piezoelectric pressure transducers at four different circumferential locations at $90^{\circ}$ intervals as indicated in Fig. 2 and at the center of Fig. 6. Traces (a), (b), (c), and (d) are direct oscilloscope recordings with Traces (a) and (c) taken from one and Traces (b) and (d) from a second screen. Thus the two sets (a) and (c) and (b) and (d) each have the same time scale. Each trace shows a somewhat different pressure pattern from the others, which indicates that the flow pattern inside the FAT is highly non-uniform. These pressure traces are representative of 30 sets of pressure recordings obtained for different Mira Gel runs.

The sets of pressure traces from the different runs were by no means identical; however, all of them exhibited two characteristics. The first is that the arrival time for the shock in Trace (a) is always ahead of that in Trace (c) by about $30-50 \mu \mathrm{s}$, and that the arrival times for the shocks in Traces (b) and (d) are always about the same. Second, the highest pressure peak is always recorded at the bottom of the FAT, i.e. on Trace (c). Based on these common properties and 

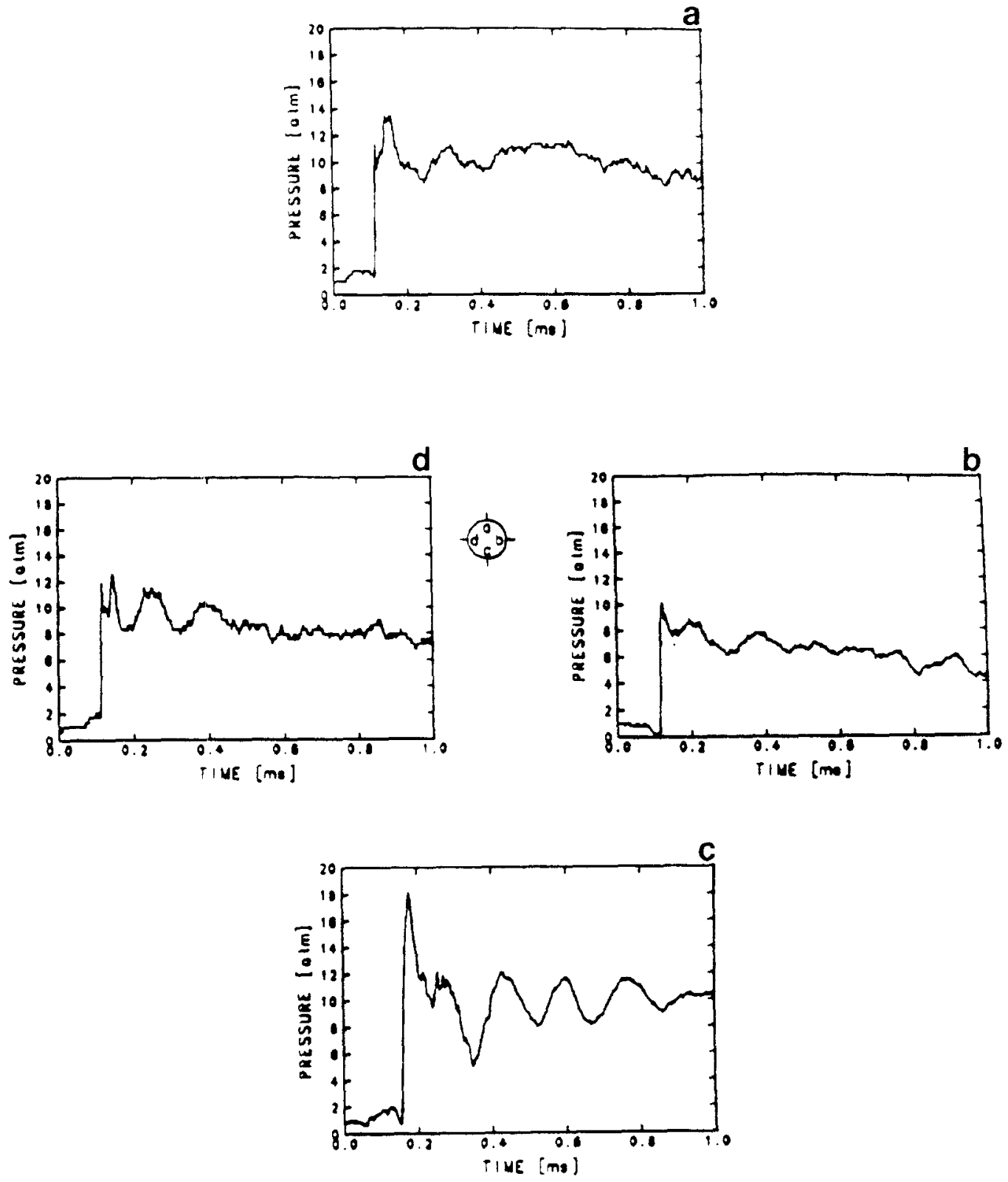

Fig. 6a-d. Pressure profiles around the inside wall of the FAT at $x=60 \mathrm{~m}$. Dust layer: Mira Gel, $\sigma=600 \mathrm{~g} / \mathrm{m}^{3}$, layer length $67 \mathrm{~m}$. Location: a top, b right, $\mathrm{c}$ bottom, $\mathbf{d}$ left. Figure faces in direction of flow

from an examination of the pressure traces it was postulated that the quasi-detonation wave structure may have the form shown in Fig. 7 (b). For reference, Traces (a) and (c) of Fig. 6 are also shown on this figure. Through the transformation of $t=x / D$, where $t$ is time in milliseconds, $x$ is distance in meters, and $D$ is the detonation velocity $(=1010 \mathrm{~m} / \mathrm{s})$, the scale for the sketch of the wave structure becomes identical to the scale of the pressure recordings. This transformation is justified by the fact that the flame velocity was essentially constant at the location of the pressure transducers. This run represents a typical quasi-detonation whose propagation velocity is approximately $1010 \mathrm{~m} / \mathrm{s}$.

It is postulated that the leading shock of the quasidetonation is essentially a triple shock configuration with a Mach stem at the bottom of the FAT as shown in Fig. 7(b), followed by a combustion zone generating a series of compression and expansion waves. The nature of this system of waves could not be deduced from the pressure traces, and so their probable location is indicated by a series of question marks on the figure. Since the dust concentration will generally be highest near the dust layer at the bottom of the FAT the quasi-detonation could be approximated as one propagating through two adjacent explosive layers with different fuel concentrations. Hence it is not surprising that the triple shock structure shown in Fig. 7 (b) is similar to that which occurs when a detonation propagating in a gaseous layer of explosive suddenly comes into contact with a second, bounding explosive layer as observed by Liu et al. (1988) and simulated numerically by Oran et al. (1992). The differences in the present case are that there is no discontinuous change in the explosive composition in the vertical direction, and that there is two phase combustion. Another significant difference is that in the gaseous case mentioned above the detonation propagates faster in rich mixtures than in lean 


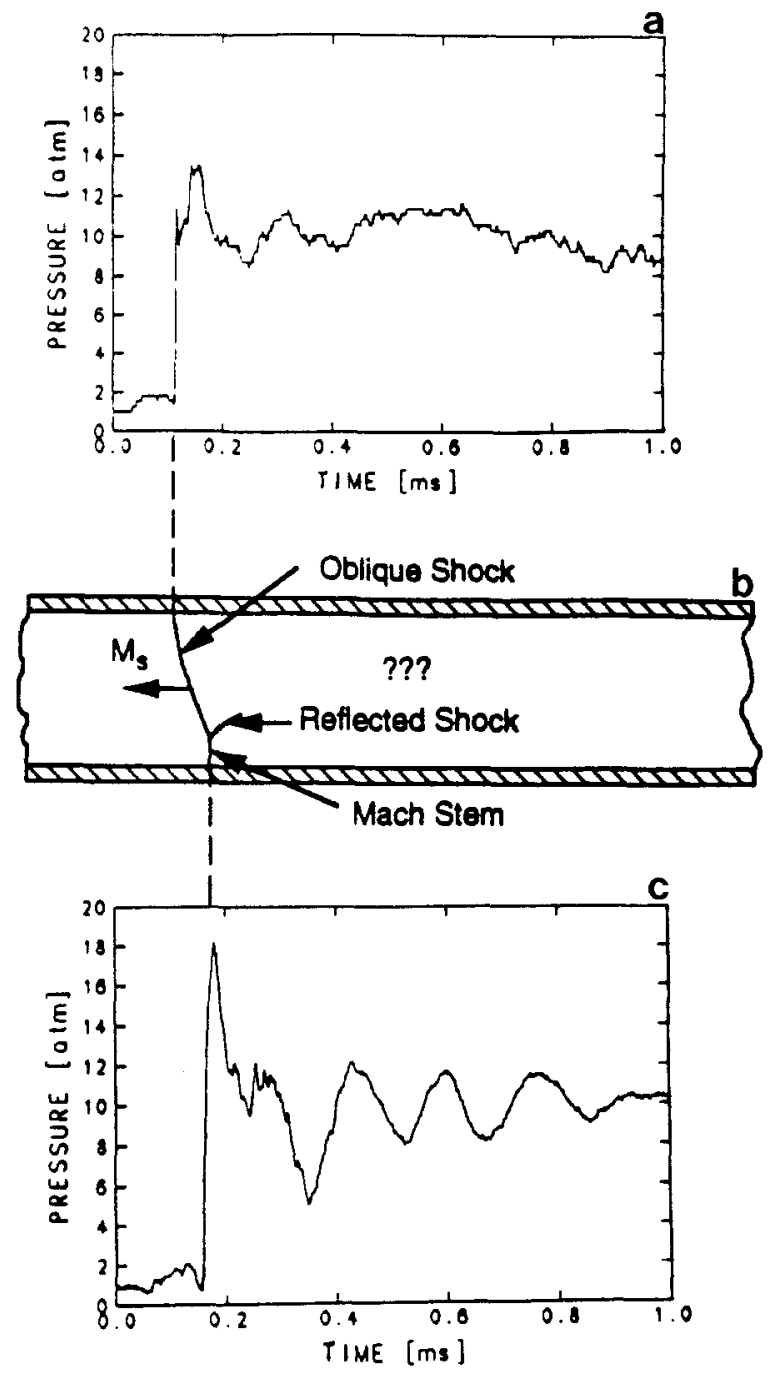

Fig. 7a-c. Postulated triple shock configuration $\mathbf{b}$ for quasi-detonation based on pressure traces a top of FAT, and $\mathbf{c}$ bottom. Question marks indicate insufficient information to postulate flow field

mixtures, while in this study it seems just the opposite, i.e., quasi-detonations travel faster in leaner mixtures as indicated in Table 2. This differences is probably a two phase effect and a consequence of the increased drag forces exerted by the particles on the gaseous media as the dust concentration increases.

As reported by Zhang and Groenig (1991), the presuspended dust/oxygen (or oxygen enriched air) mixtures generally supported a spinning detonation structure with one or two spinning heads as opposed to the one described above. Spinning detonations can also be observed in nearlimit gaseous mixtures or in relatively less reactive gaseous mixtures (e.g., methane/air) as already indicated above. The structure of spinning detonations has been discussed extensively by Fay (1952), and experimental results have been presented by Schott (1965), and by Voitsekhovskii et al. (1969). There is also the possibility that a spinning detonation structure exists in the pre-layered dust/air detonations considered here. Figure 8 shows the pressure distributions measured in a wheat dust run, which is a typical for both wheat dust and wood flour. Figure 5 shows that in the case of wheat dust the combustion wave reached a velocity on the order of $2000 \mathrm{~m} / \mathrm{s}$ at the end of the FAT, and it can be seen that the wave patterns in Fig. 8 are quite different from those for Mira Gel shown in Fig. 6. The most prominent difference is that there is almost no time lag between Traces (a) and (c) and that the highest pressure peak was not always recorded at the bottom of the tube. The peak pressure was significantly higher than that recorded for the Mira Gel runs. These results suggest the possibility of a detonation with a spinning structure. Once again, the concentration is still non-uniform along each cross-section of the FAT; however, because of the smaller density of wheat dust relative to Mira Gel, the former must be more completely dispersed than the latter, and the detonation structure appears to reflect this difference. Nevertheless, there is still not enough evidence to definitely establish the detonation structure for wheat dust. The main reason that Mira Gel and wheat present very different pressure wave patterns is most likely due to the different dust dispersion mechanisms which play a key role in layered detonations. For Mira Gel, the dust concentration is likely to be significantly higher near the bottom of the FAT and lower near the top. For wheat dust or wood flour, dust is more uniformly distributed across each section of the FAT, and the pressure traces are somewhat similar to those observed in pre-suspended dust detonations by Zhang and Groenig (1991).

\section{Conclusions}

Based on the current experimental data, it can be concluded that inserting grids inside the FAT enhances the flame propagation process near the end of the FAT. Varying the concentration of the dust mixture in the premixed primary section of the FAT does not seem to significantly vary the flame acceleration process, at least over the range of concentrations considered here. However, it is absolutely essential, for the present experimental setup, to include the pre-mixed section to initiate a layered detonation.

For wheat dust the measured detonation velocities at the end of the FAT were found to be in essential agreement with the calculated C-J velocity, but the measured pressure was substantially higher than the computed C-J pressure.

It was found that DDT requires much longer transition distances in pre-layered dust/air mixtures, than in presuspended dust/oxidizer mixtures. The added distance is, apparently, required for the dust layer to be dispersed into the surrounding gas. A minimum distance exists for DDT in layered dust explosions, and in this study this length was found to be in the range of $x=55-65 \mathrm{~m}$ or $x / d=183-217$. Since pre-layered dust flame propagation is controlled by many factors, the value $x / d$ obtained here may not be universally applicable to other test devices.

There is evidence that for Mira Gel starch the quasidetonation structure consists of a triple shock configuration which involves a Mach reflection. This structure appears to reflect the non uniform distribution of Mira Gel within the FAT, which may also explain why the propagation velocities at the end of the FAT is much lower for Mira Gel dust than for wheat dust. For wheat dust and wood flour there is preliminary evidence of a spinning structure. 

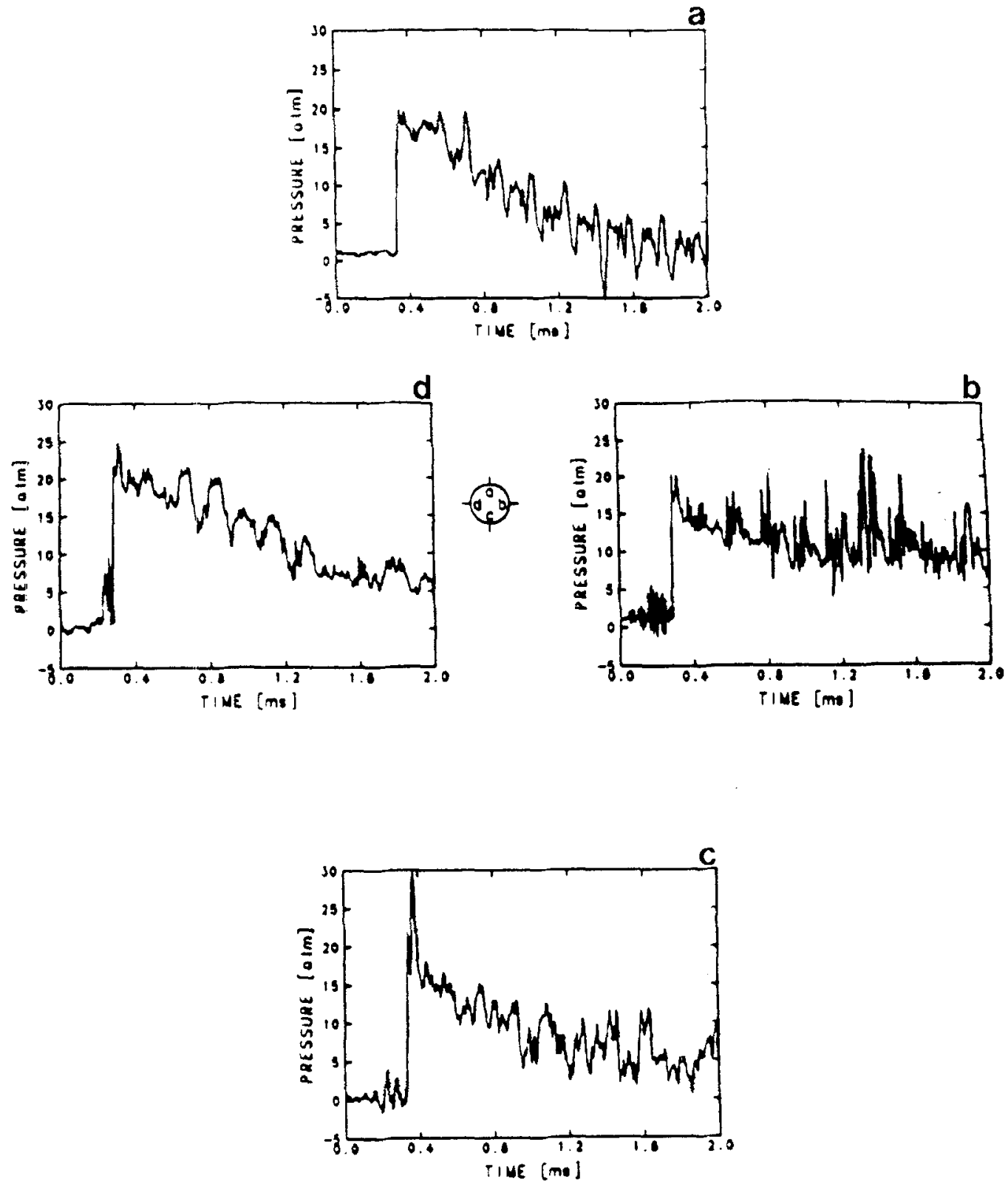

Fig. 8a-d. Pressure profiles around the inside wall of the FAT at $x=60 \mathrm{~m}$. Dust layer: wheat. $\sigma=350 \mathrm{~g} / \mathrm{m}^{3}$, layer length $67 \mathrm{~m}$. Location: a top. b right, $\mathrm{c}$ bottom, $d$ left. Figure faces in direction of flow. Test conditions as given in Table?

The structure of layered dust detonations is extremely complicated, due to the shock-flame interaction and the twophase flow and chemical reaction. The detailed nature of these complex processes requires further investigation.

Acknowledgement. This study is sponsored by the National Institute of Occupational Safety and Health of the U.S. Department of Health and Human Services under Grant No. OH01122-09.

\section{References}

Cybulski W (1975) Coal dust explosions and their suppression. Foreign Scientific Publications Department of the National Center for Scientific, Technical, and Economic Information. Warsaw Poland

Fay JA (1952) A mechanical theory of spiming detonation. I Chem Phys 20:942-950

Gordon S, McBride BJ (1971) Computer program for calculation of complex chemical equilibrium compositions, rocket performance, incident and reflected shocks, and Chapman-Jouguet detonations. NASA SP273

Kauffman CW, Sichel M, Wolanskj P (1991) Dust related detonations. In: Borissov AA (ed) Dynamic structure of detonation in gaseous and dispersed media. Kluwer Academic Boston, pp 267-311

Kauffman CW, Sichel M, Wolanski P (1992) Research on dust explosions at the university of Michigan. Powder Technology 71:119-134

Lebecki K, Sliz J, Dyduch Z (1991) Critical dust layer thickness for combustion of grain dust. In: Kuhl AL et al. (eds) Progress in Astronautics and Aeronautics. AIAA, New York, vol 132, pp 51-58

Lee JHS (1988) Dust explosion: an overview. In: Groenig H (ed) Proceeding of the sixteenth international symposium on shock tubes and waves. VCH New York, pp 209-215

Li YC, Alexander CG, Wolanski P, Kauffman CW, Sichel M (1993) Experimental investigations of accelerating flames and transition to detonation in layered grain dust. In: Kuhl AL et al. (eds) Progress of astronautics and aeronautics. AIAA, New York, vol 154, pp 170-184

Li YC (1993) Deflagration to detonation transition fueled by dust layers PhD thesis. University of Michigan. Ann Arbor Michigan

Liu JC, Kauffman CW, Sichel M (1988) Lateral interaction of detonating 
and detonable gaseous mixtures. In: Kuhl AL et al. (eds) Progress of astronautics and aeronautics. AIAA, New York, vol 114, pp 264-283

Matsui H, Komamiya K (1986) An experimental study of soot film detonations. In: Bowen JR et al. (eds) Progress of astronautics and aeronautics. AIAA, New York, vol 106, pp 559-570

Oran ES, Jones DA, Sichel M (1992) Numerical simulations of detonation transmission. Proc. Roy. Soc. Lond, A, 436:267-297

Schott GL (1965) Observations of the structure of spinning detonation. Physics of Fluids 8:850-865

Srinath SR (1985) Flame propagation due to layered combustible dust. PhD thesis. University of Michigan, Ann Arbor Michigan

Urtiew PA, Oppenheim AK (1966) Experimental observations of the transition to detonation in an explosive gas. Proc. Roy. Soc. Lond, A, 295:13-28
Verakis HC, Nagy J (1987) A brief history of dust explosions. In: Cashdollar KL, Hertzberg M (eds) Industrial dust explosions, ASTM STP 958. ASTM, Philadelphia, pp 342-350

Voiltsekhovskii BV, Mitrofanov VV, Topchian ME (1969) Investigation of the structures of detonation waves in gases. Twelfth symposium (international) on combustion. Combustion Institute, Pittsburgh, pp 829-837

Wolanski P, Sacha W, Zelesinski M (1990) Effect of dust concentration on detonation parameters in grain dust-air mixtures. Proceedings of the fourth international colloquium on dust explosions. Porabka-Kozubnik Poland, pp 355 -370

Zhang F, Groenig H (1991) Transition and structure of dust detonations. In: Borissov AA (ed) Dynamic structure of detonation in gaseous and dispersed media. Kluwer Academic, Boston, pp 157-213 